\title{
Air jet impingement to reduce hot strip wave on a run-out table
}

\author{
Young Yun Woo ${ }^{1}$, Sang Wook $\operatorname{Han}^{1}$, Jin Rae $\mathrm{Cho}^{2}$, and Young Hoon Moon ${ }^{1, *}$ \\ ${ }^{1}$ School of Mechanical Engineering, Pusan National University, Busan 46241, Korea \\ 2 Department of Naval Architecture and Ocean Engineering, Hongik University, Sejong 339-701, Korea
}

Received: 12 June 2018 / Accepted: 20 September 2018

\begin{abstract}
Traveling stability is necessary for a hot rolled strip on a run-out table before coiling in steel mills because it affects the process efficiency and the quality of the rolled products. This study proposes an air jet impingement system to reduce the hot strip wave that occurs during tensionless travel in a run-out table before the top end of the strip reaches the coiler mandrel. The finite element method was used to examine the pressure distributions on the moving strip associated with the parameters in the air jet systems. Experiments were carried out on a pilot-scale air jet impingement system to investigate the performance. The results show that the air impingement in the moving direction effectively reduces the strip wave, and the simulated results agree with the actual measurements and observations.
\end{abstract}

Keywords: Air jet impingement / hot strip rolling / run out table / strip wave

\section{Introduction}

There is high demand for hot-rolled strips with high standards of surface quality, dimension control, and mechanical properties. Hot strip mills reheat semi-finished steel slabs to near their melting point and then roll them to make them thinner and longer through successive roughing and finishing rolling mill stands driven by motors. Finally, the lengthened steel sheet is coiled up for transport to the next process. Figure 1 shows a schematic of a hot strip mill layout.

After the steel strip is hot rolled, it is then subjected to cooling on a run-out table. The qualities of the final product significantly depend on the cooling process, including the metallurgical and mechanical properties and the flatness [1-4]. The strip may show an unstable wave when traveling on the run-out table until the top end reaches the coiler mandrel. Traveling stability is needed to maintain a flat surface, which can be improved by examining the strip wave that develops at the top end of the strip when traveling on a run-out table. The ultimate reason for the occurrence of a strip wave is the lack of tension between the finishing mill stand and the coiler mandrel before the top end of the strip reaches the coiler mandrel.

Adequate control of the temperature, flatness, camber, and crown in the finishing mill is a critical concern [5-7]. An effective prevention method for use on the run-out table is required. A finite element model was established to investigate how the strip flatness changes during cooling

\footnotetext{
* Corresponding author: yhmoon@pusan.ac.kr
}

on the run-out table, and the temperature, phase transformation, and stress/strain were fully coupled to analyze the internal stress evolution [8]. To simulate the deformation behavior of the steel strip on a run-out table, the phase transformation kinetics, temperature, and deformation behavior of the steel should be analyzed simultaneously [9].

Water-jet impingement has been widely applied to accelerate cooling moving strips on a run-out table. The complex heat transfer mechanism during water jet impingement cooling is hard to understand. The heat transfer process during cooling process depends on a number of parameters, such as the water flow rate, nozzle geometry, coolant temperature, and moving speed of the target material [10]. Despite numerous efforts to simulate accelerated cooling by numerical method, it still remains a challenging task. Furthermore, the validity of empirical models is usually restricted to a limited range of process parameters. Hence, the goal of ongoing cooling studies is to develop a more versatile analytical tool to understand the fundamental physics that occur during jet impingement. Liquid jet impingement is an effective cooling method used in many applications because of its capacity to transfer very high heat flux $[11,12]$.

The impingement on the hot flat strip is very complicated, and it has often been dealt with using experiments and empirical models. The cooling problem of the steel strip on a run-out table is a special case of jetimpingement cooling of a flat plate. Many different techniques are used to cool steel plates on a run-out table, such as impinging water at different angles with different types of nozzles, sprays, and liquid curtains. Impinging air 


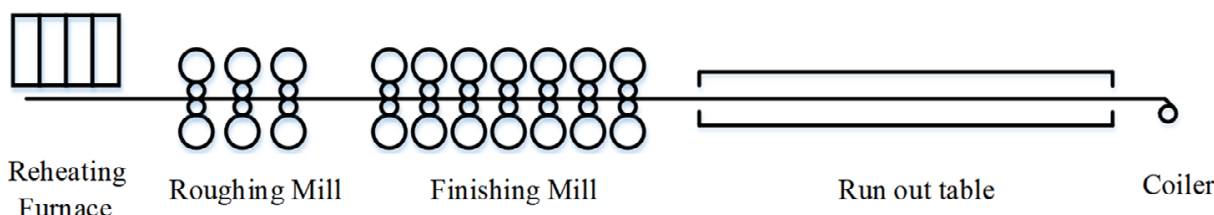

Fig. 1. Schematic of a hot strip mill layout.

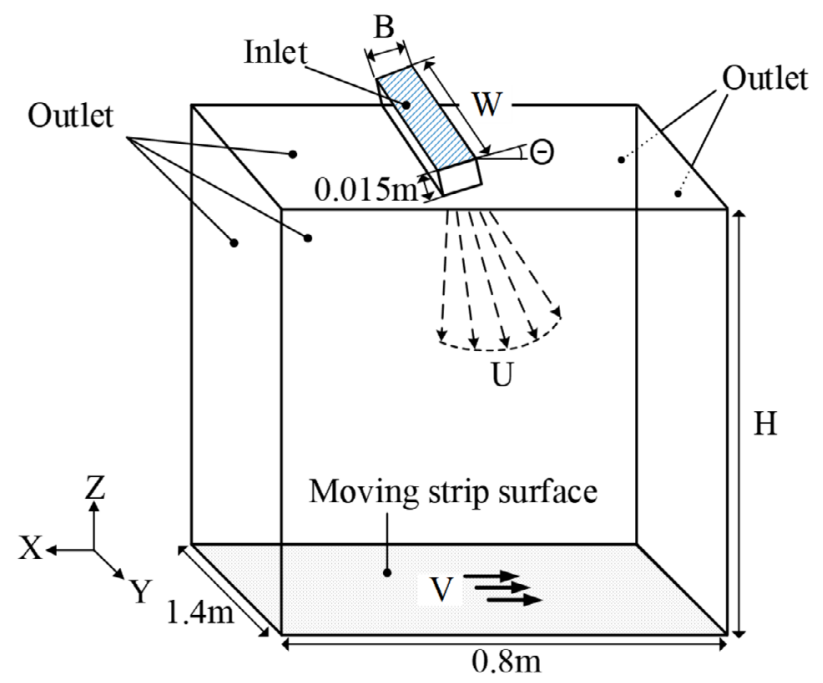

Fig. 2. Domain and boundary conditions for finite element analysis.

cooling techniques are very useful for many applications, such as cooling of combustion engines, drying paper, cooling critical machinery structures, and annealing metal plates and electronic microchips [13]. Extensive studies on jet impingement have been conducted [14-16]. A fluidstructure interaction simulation model of tensor skin impinging with water has been established using FE method [17,18]. Air jet impingement is a highly effective heat transfer technology, and improving its heat transfer efficiency is important for engineering and industrial applications $[19,20]$. And the breakup of solid particles impinged by a high-velocity air gas and water has also been studied $[21,22]$.

This study examines the effectiveness of air jets impinging on a hot strip for reducing the wave that occurs during tensionless travel on a run-out table. Finite element analysis has also been performed to provide processing condition that can enhance travelling stability. Pilot-scale experiments were carried out to validate the performance of the system.

\section{Finite element analysis}

A finite element model was established to analyze the effect of process parameters on the reduction of traveling waves during air jet impingement. The model includes a $1.4 \mathrm{~m} \times 0.8 \mathrm{~m}$ rectangular strip and a rectangular nozzle that has a height $(B)$, a width $(W)$ placed at a height $H$ over the middle of the strip as shown in Figure 2. The
Table 1. Finite element analysis conditions.

\begin{tabular}{ll}
\hline Solver & Pressure based \\
\hline Model & K-epsilon (2 eqn) \\
K-epsilon model & Standard \\
Near-wall treatment & Enhanced wall functions [13] \\
Temperature & $300 \mathrm{~K}$ \\
Pressure & $\mathrm{Pa}$ \\
Mesh type & Tetrahedral \\
Mesh size & $0.2869-28.3790 \mathrm{~mm}$ \\
\hline
\end{tabular}

computational domain is modeled in $3 \mathrm{D}$. The standard $k-\varepsilon$ turbulence model and enhanced wall function for the truncated bounded boundary were used for the simulation [23]. To couple the velocity and pressure, the SIMPLE algorithm and second-order accurate schemes were used in Fluent ANSYS Ver.14. A fixed velocity with the turbulence intensity of $5 \%$ and the turbulent viscosity ratio of 10 is applied as a boundary condition at the nozzle inlet. The outer nozzle surface is specified as an adiabatic wall, and the strip surface is specified as a moving wall with a speed of $10 \mathrm{~m} / \mathrm{s}$ and no slip conditions. All the other surfaces in the computational domain are specified as outlet boundary conditions with atmospheric pressure and temperature. The analysis conditions are summarized in Table 1.

\section{Results and discussion}

\subsection{Finite element analysis of air jet impingement system parameters}

The pressure and flow velocity distributions in the impingement region were mainly investigated. The pressure distribution and flow velocity on the moving strip after air jet impingement are shown in Figure 3.

The spread of the air jet depends on the nozzle shape, which results in a pressurized rectangular region that gradually forms soon after the impingement starts. However, the pressure decreases as the distance from the focal point increases. The pressure distribution was measured along the center line in the moving direction. The forward flow velocity in the moving direction of the strip is larger than that of the backward flow. These flow velocities are beneficial for reducing the traveling wave of the hot strip. This result also confirms the industrial practice of using water impingement for accelerated cooling of hot steel plates [24-27]. 


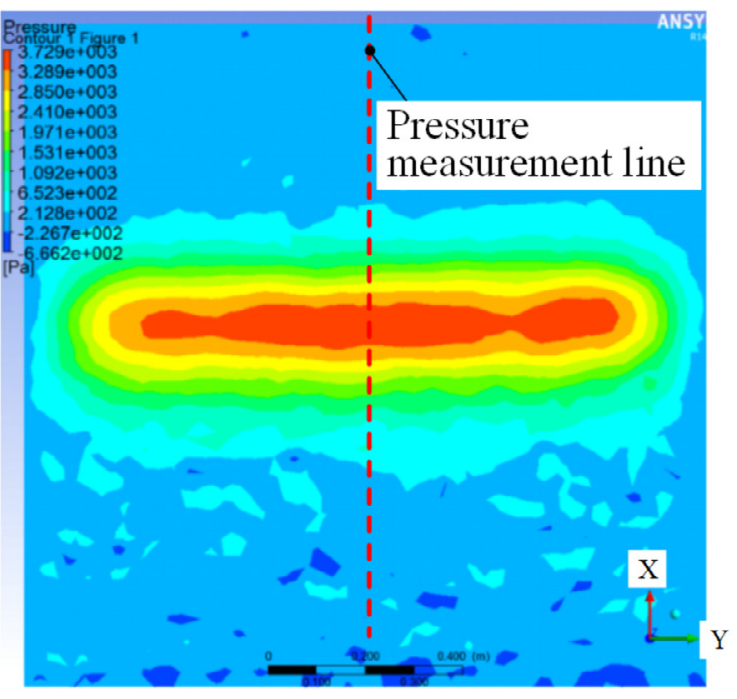

(a)

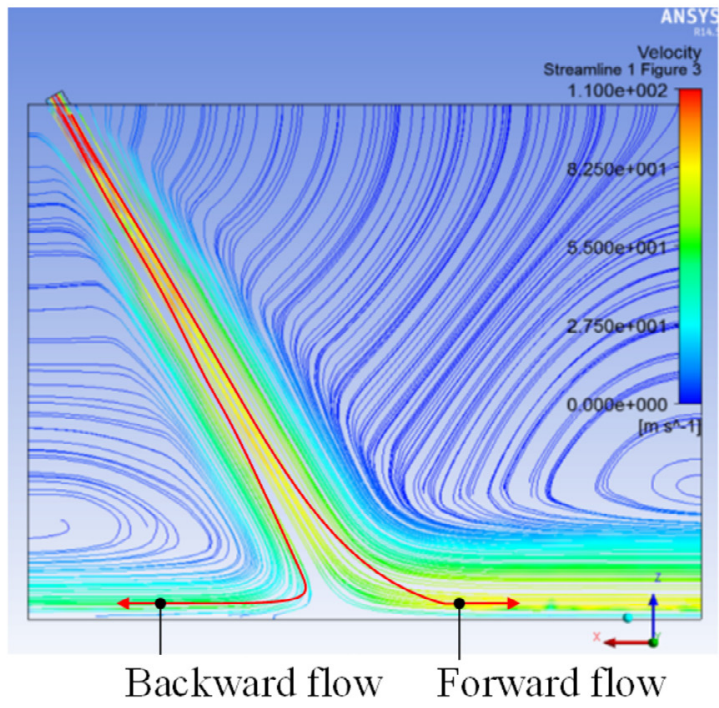

(b)

Fig. 3. (a) Pressure distribution and (b) flow velocity obtained by finite element simulation: $W=1200 \mathrm{~mm}, B=40 \mathrm{~mm}$, $H=1100 \mathrm{~mm}, V=10 \mathrm{~m} / \mathrm{s}, U=150 \mathrm{~m} / \mathrm{s}, \theta=20^{\circ}$.

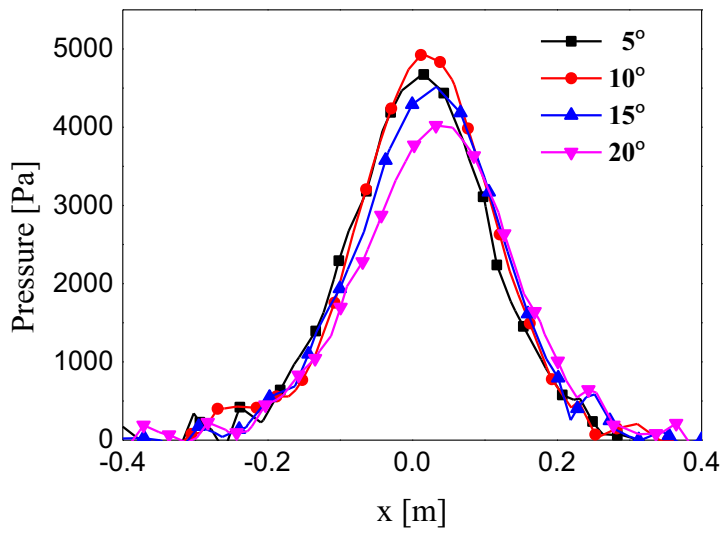

(a)

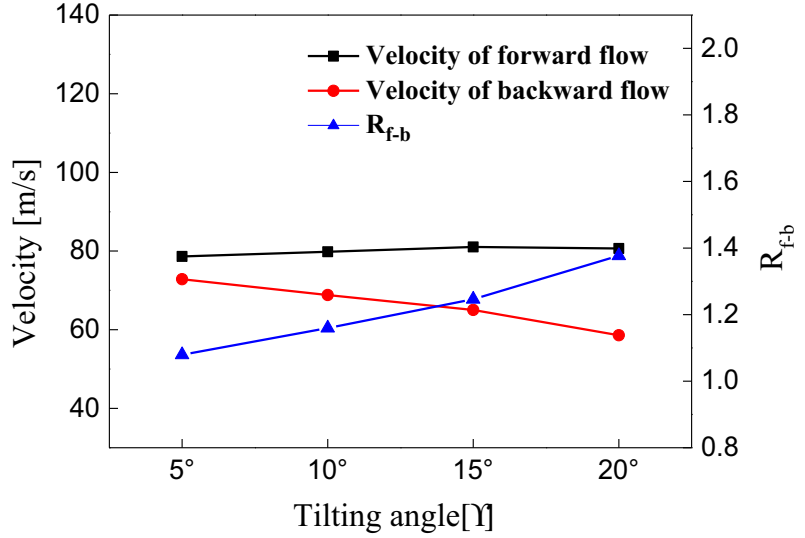

(b)

Fig. 4. Effect of nozzle tilt angle on (a) pressure distribution and (b) flow velocity.

To determine the effects of the nozzle geometry on the pressure and flow velocity distributions, simulations were carried out using various nozzle tilting angles, nozzle heights, and inlet velocities. Figure 4 shows the effects of the nozzle tilt angle on the pressure and flow velocity distributions at $W=1200 \mathrm{~mm}, B=40 \mathrm{~mm}, H=1100 \mathrm{~mm}$, $V=1 \mathrm{~m} / \mathrm{s}$, and $U=150 \mathrm{~m} / \mathrm{s}$. As shown in Figure $4 \mathrm{a}$, the maximum impingement pressure occurs when the tilt angle is $10^{\circ}$. The maximum impingement pressure is largely dependent on the pressure distribution, and tilt angles larger than $10^{\circ}$ result in lower pressures due to the pressure dissipation.

The forward flow velocity in the moving direction of the strip is larger than that of the backward flow. From the perspective of traveling stability, higher forward flow velocity is more advantageous for reducing the wave of the hot strip. The ratio between the forward and backward flow velocities $R_{\mathrm{f}-\mathrm{b}}$ is shown in Figure $4 \mathrm{~b}$. As $R_{\mathrm{f}-\mathrm{b}}$ increases with increasing tilt angle, a higher nozzle angle is more advantageous for reducing the wave of the hot strip. Hence, simultaneous consideration of the maximum pressure and $R_{\mathrm{f}-\mathrm{b}}$ is necessary to determine the optimum nozzle angle.

Figure 5 shows the effect of the distance between nozzle and strip on the pressure and flow velocity distributions at $W=1200 \mathrm{~mm}, \quad B=40 \mathrm{~mm}, V=1 \mathrm{~m} / \mathrm{s}, \quad U=150 \mathrm{~m} / \mathrm{s}$, and $\theta=10^{\circ}$. As shown in Figure $5 \mathrm{a}$, the maximum impingement pressure occurs when the distance between the nozzle and strip is $900 \mathrm{~mm}$. The maximum impingement pressure is largely dependent on the concentrated pressure distribu- 


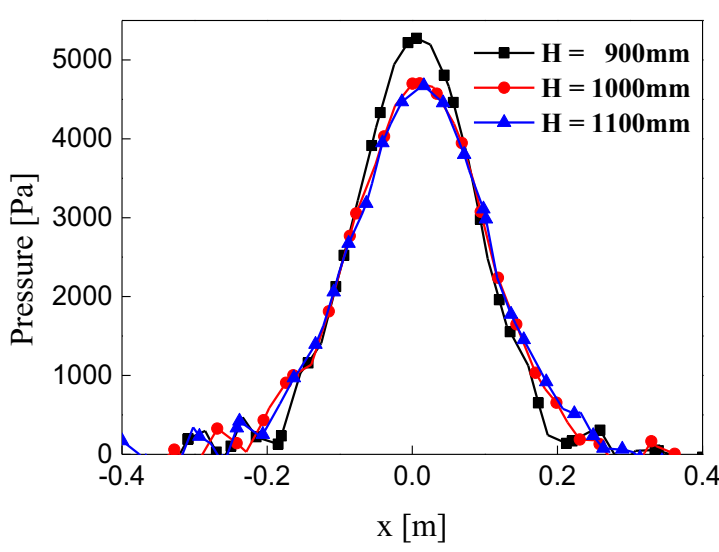

(a)

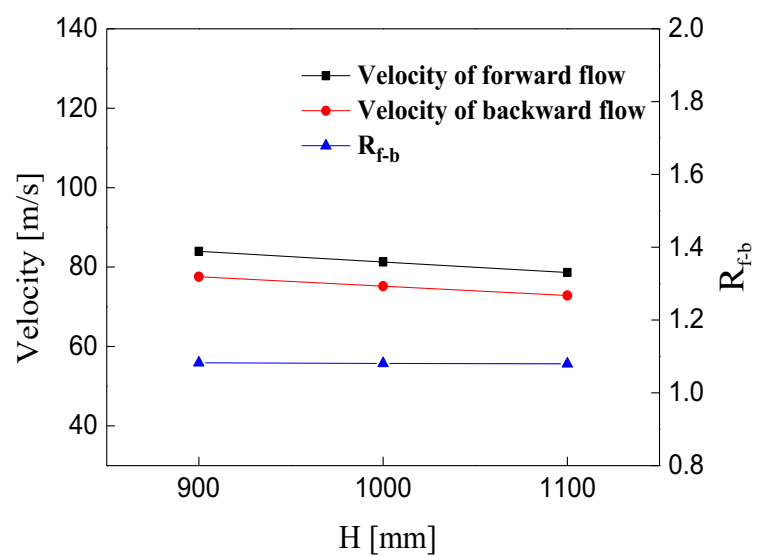

(b)

Fig. 5. Effect of the distance between the nozzle and strip on (a) pressure distribution and (b) flow velocity.

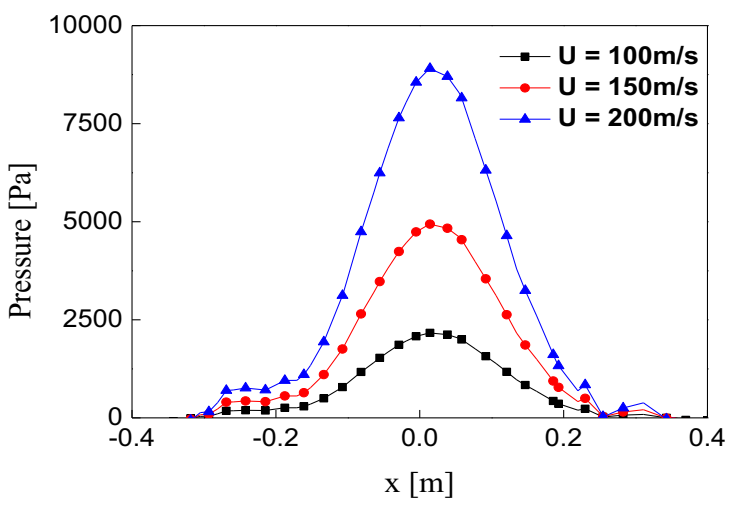

(a)

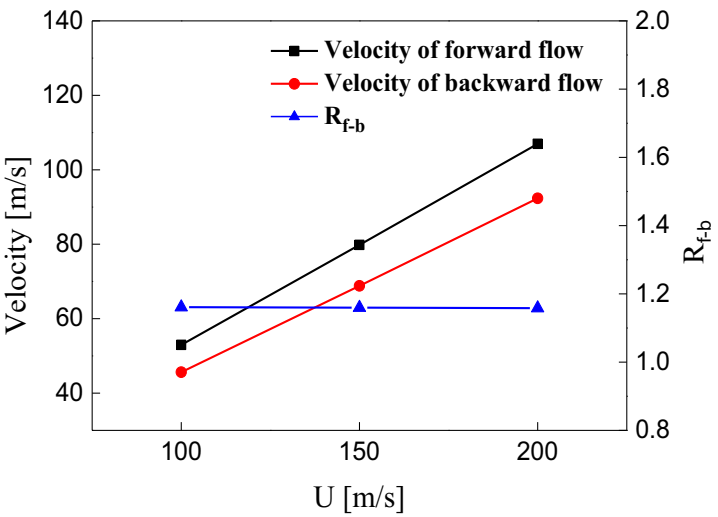

(b)

Fig. 6. Effect of nozzle inlet velocity on (a) pressure distribution and (b) flow velocity.

Table 2. Simulations according to the height $(B)$ and width $(W)$ of the air nozzle.

\begin{tabular}{llllll}
\hline Schedule & Case 1 & Case 2 & Case 3 & Case 4 & Case 5 \\
\hline Nozzle height $(B)(\mathrm{mm})$ & 68.6 & 60.0 & 53.3 & 48.0 & 43.6 \\
Nozzle width $(W)(\mathrm{mm})$ & 700 & 800 & 900 & 1000 & 1100 \\
\hline
\end{tabular}

tion, and a smaller distance results in higher impingement pressure at a given nozzle angle. The forward and backward flow velocities decrease with increasing distance between the nozzle and strip. The ratio between the forward and backward flow velocities $R_{\mathrm{f}-\mathrm{b}}$ is shown in Figure $5 \mathrm{~b}$. As shown in the figure, the ratio is not significantly influenced by the distance between the nozzle and strip.

Figure 6 shows the effect of the nozzle inlet velocity on the pressure and flow velocity distributions at $W=1200 \mathrm{~mm}, B=40 \mathrm{~mm}, H=1100 \mathrm{~mm}, V=10 \mathrm{~m} / \mathrm{s}$, and $\theta=10^{\circ}$. As shown in Figure $6 \mathrm{a}$, the maximum impingement pressure occurs when the nozzle inlet velocity is $200 \mathrm{~m} / \mathrm{s}$ because the maximum impingement pressure is proportional to the inlet velocity. The forward and backward flow velocities increase with increasing nozzle inlet velocity. As shown in Figure $6 \mathrm{~b}, R_{\mathrm{f}-\mathrm{b}}$ is not significantly influenced by the nozzle inlet velocity.

Figure 7 shows the effect of the nozzle dimensions on the pressure and flow velocity distributions at $H=1100 \mathrm{~mm}$, $V=10 \mathrm{~m} / \mathrm{s}, \quad U=150 \mathrm{~m} / \mathrm{s}$, and $\theta=10^{\circ}$. Different nozzle heights and widths were simulated. Table 2 shows the cross-sectional dimensions of the trial rectangular nozzles, which have an exit area of approximately $48,000 \mathrm{~mm}^{2}$.

As shown in Figure 7a, the maximum impingement pressure increases with decreasing nozzle width. The forward and backward flow velocities also increase with decreasing nozzle width. As shown in Figure $7 \mathrm{~b}, R_{\mathrm{f}-\mathrm{b}}$ is not significantly influenced by the nozzle dimensions. 


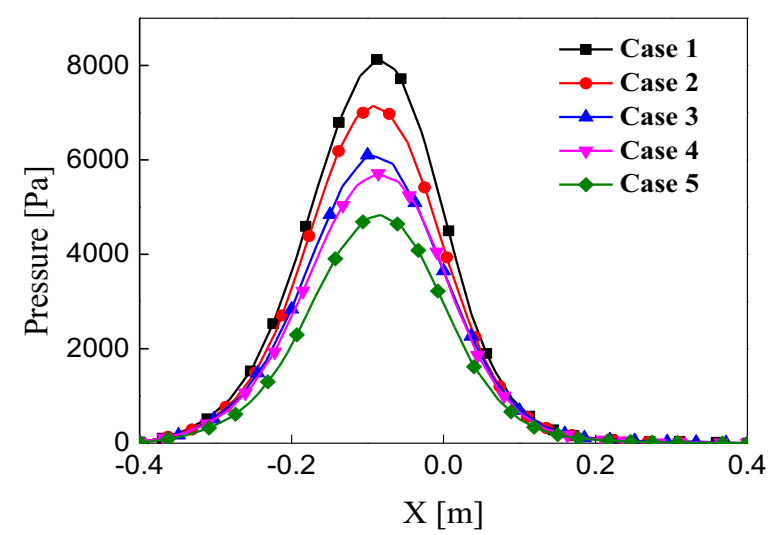

(a)

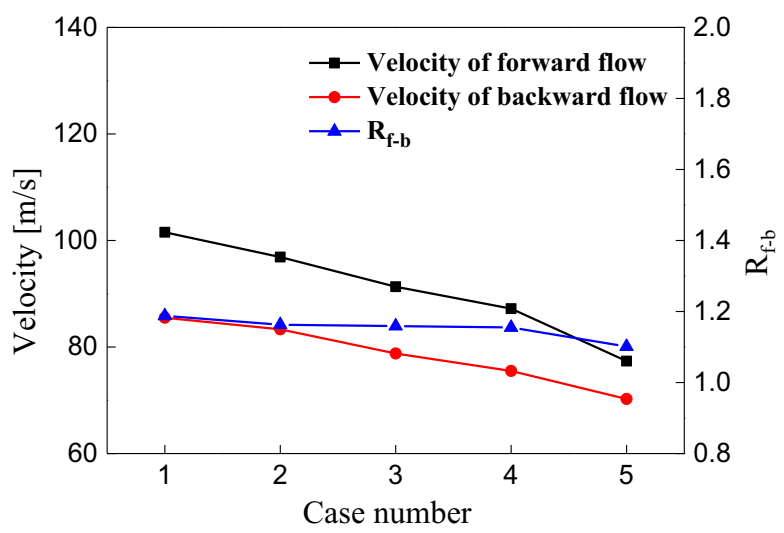

(b)

Fig. 7. Effect of nozzle shape on (a) pressure distribution and (b) flow velocity.

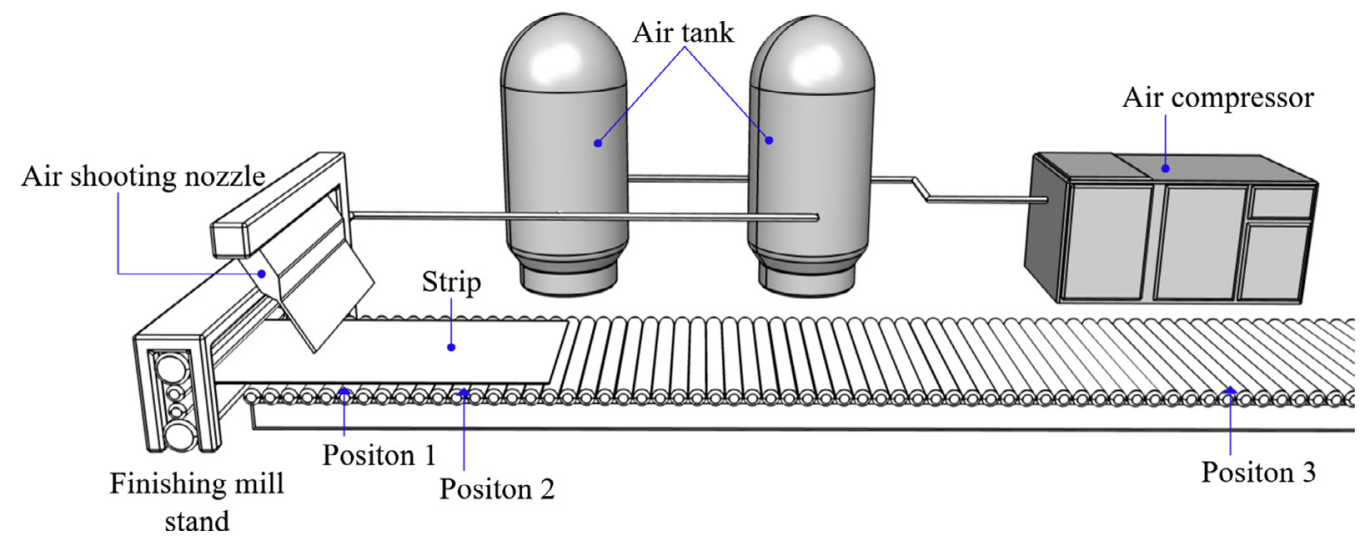

Fig. 8. Schematic of the pilot-scale air jet impingement system.

Table 3. Classification of traveling stability index.

\begin{tabular}{lllll}
\hline TS index & 0 & 1 & 2 & 3 \\
\hline Height of wave $(h)$ & Below $0.2 \mathrm{~m}$ & $0.2-0.4 \mathrm{~m}$ & $0.4-0.6 \mathrm{~m}$ & Above $0.6 \mathrm{~m}$ \\
Wave length $(l)$ & Above $3.0 \mathrm{~m}$ & $1.0-3.0 \mathrm{~m}$ & $1.0-3.0 \mathrm{~m}$ & Below $1.0 \mathrm{~m}$ \\
\hline
\end{tabular}

\subsection{Experimental validation of air jet impingement system}

Experimental investigations were carried out to validate the performance of the air jet impingement system for reducing the traveling wave. A schematic of the pilotscale facility is shown in Figure 8. The setup mainly comprises an air compressor, air tanks, a rectangular air jet nozzle, and a computer for data collection and control. High-pressure air is supplied by an air compressor. Compressed air is taken from a reciprocating compressor, which can supply air at pressures of up to 10 bar via storage tanks, a ball valve, and an automatic air filter. A float flowmeter is used to determine the air flow pressure. The actual air flow rate is controlled by a blow-off valve and the air compressor to maintain a constant pressure. The rectangular nozzle is made of 304 stainless steel, and the cross-section of the rectangular nozzle outlet is $700 \mathrm{~mm}(W) \times 68.6 \mathrm{~mm}(B)$. The vertical distance and angle of the nozzle exit with respect to the strip can be varied by a mechanically driven device.

After rolling, the end of the rolled strip is transported to the run-out table and impinged by air from the rectangular nozzle. The traveling waves were measured at three different positions. Positions 1, 2, and 3 are the outlet of the finishing mill, air impingement zone below the nozzle, and a position $40 \mathrm{~m}$ distance away from the outlet of the finishing mill, respectively. The wave is quantified using 


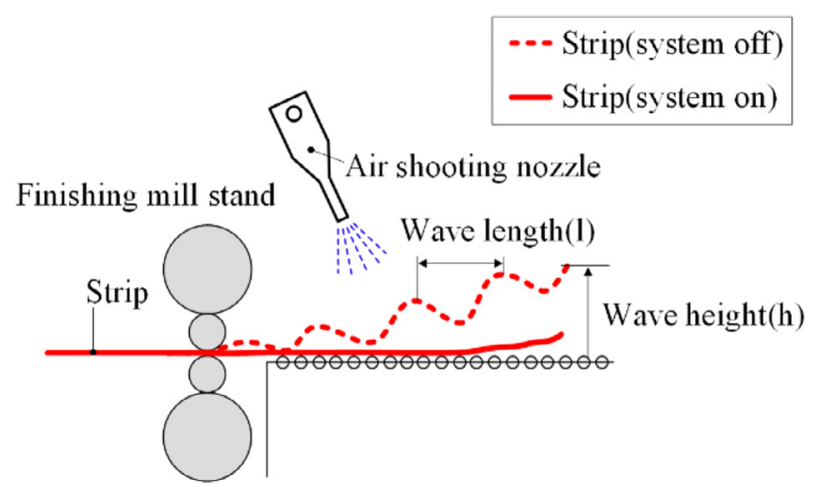

Fig. 9. Schematic of the wave height $(h)$ and wave length $(l)$.

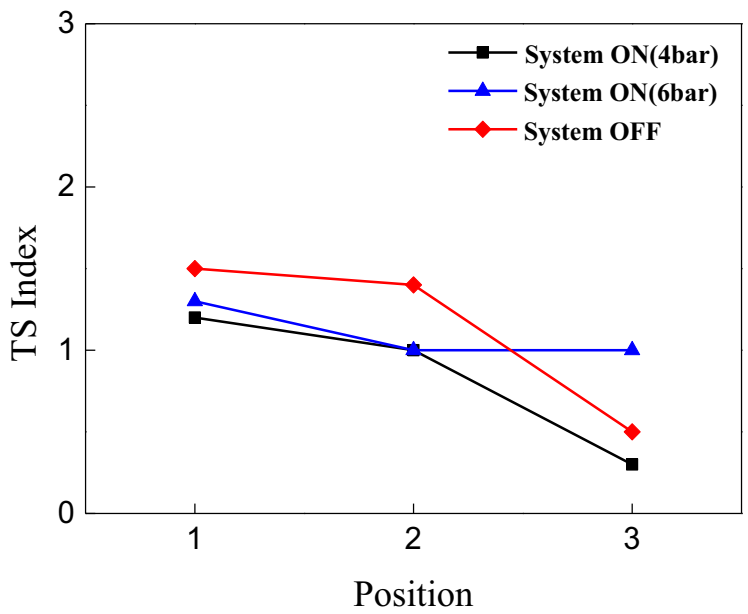

Fig. 10. Effect of air jet pressure on traveling stability $(1.82 \mathrm{~mm}$ thickness $\times 859 \mathrm{~mm}$ width strip).

the traveling stability (TS) index according to wave height $(h)$ and wave length $(l)$, as shown in Table 3 . The wave height and wave length of the strip were measured by a CCD camera as shown in Figure 9. The wave patterns at position 1,2 , and 3 were continuously measured until the head end of strip reached to coiler.

To measure the performance of the air jet impingement system, test strips with various thicknesses and widths were tested. Based on the simulations, the tilt angle of the nozzle was set to $10^{\circ}$, and the distance between the nozzle and strip was $900 \mathrm{~mm}$. Tests were performed to determine the processing conditions for the air jet pressure. Figure 10 shows the effect of the air jet pressure on the traveling stability of the hot strip. As shown in the figure, the best traveling stability occurs at an air jet pressure of 4 bar. At a higher pressure of 6 bar, the traveling at position 3 was not very stable.

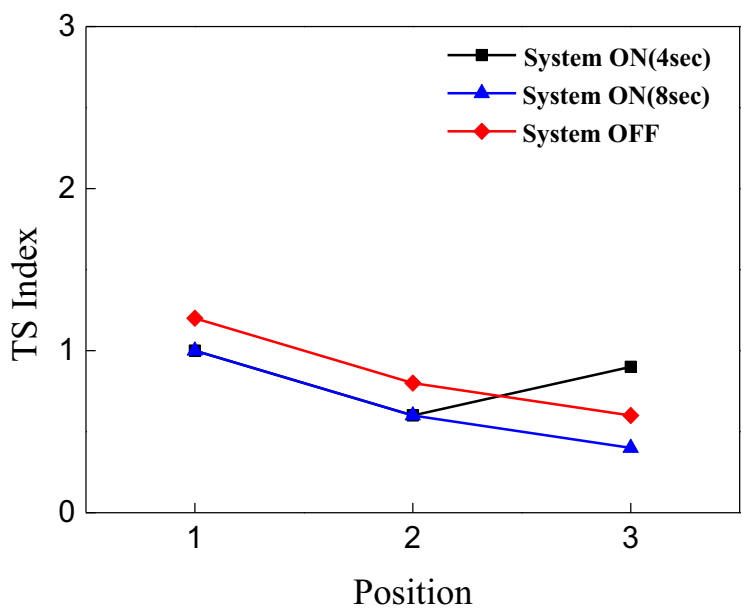

Fig. 11. Effect of air jet duration on traveling stability $(2.00 \mathrm{~mm}$ thickness $\times 1000 \mathrm{~mm}$ width strip).

Figure 11 shows the effects of the air jet duration on the traveling stability of the hot strip. As shown in the figure, the best traveling occurs with a longer air jet duration. With a shorter air jet duration of $4 \mathrm{~s}$, the traveling at position 3 was also not very stable.

The optimum operation conditions for the best performance need to be determined carefully based on the dimensions of the rolled product, material properties, and processing conditions. A nozzle outlet pressure of 4 bar was maintained for $8 \mathrm{~s}$ for the air jet impingement experiments. Figure 12 shows the test results obtained using strips with various dimensions. As shown in the figure, the traveling stability index decreases after air jet impingement. The wave is clearly reduced by the proposed system.

\section{Conclusion}

The improved traveling stability is important because it affects the process efficiency and the quality of the rolled products. This study proposes an air jet impingement system to reduce the hot strip wave that occurs during tensionless travel in a run-out table before the top end of the strip reaches the coiler mandrel. Numerical studies were performed for a proposed air jet impingement system to investigate the effects of the process parameters using the finite element method. The simulations successfully characterized the effect of process variables, such as the tilt angle of the nozzle and the distance between the nozzle and the strip on traveling stability, and the simulation results agree well with the actual measurements and observations. The pilot-scale experimental results show that the air impingement in the moving direction effectively reduces the strip wave with a high degree of reliability. 


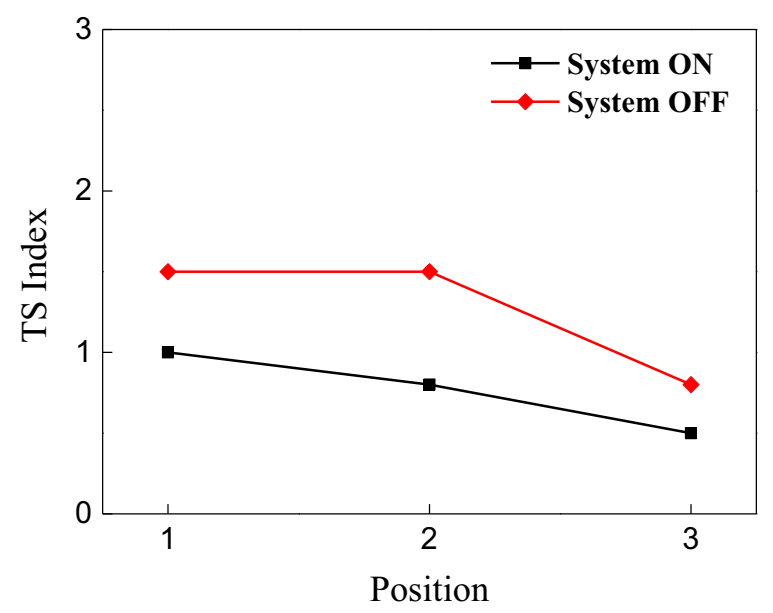

(a)

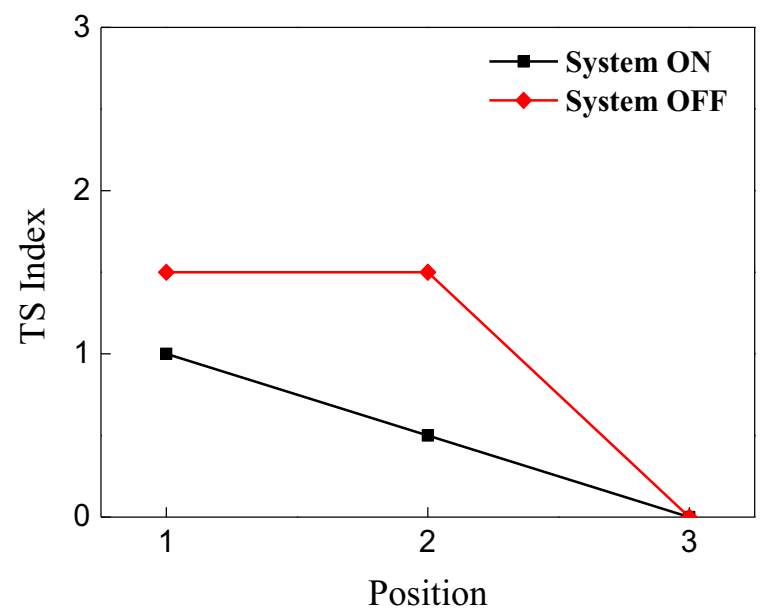

(c)

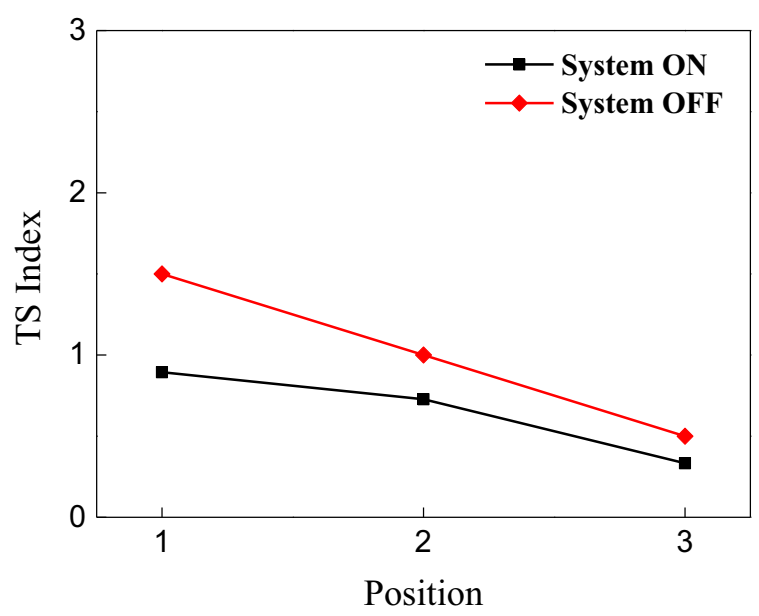

(b)

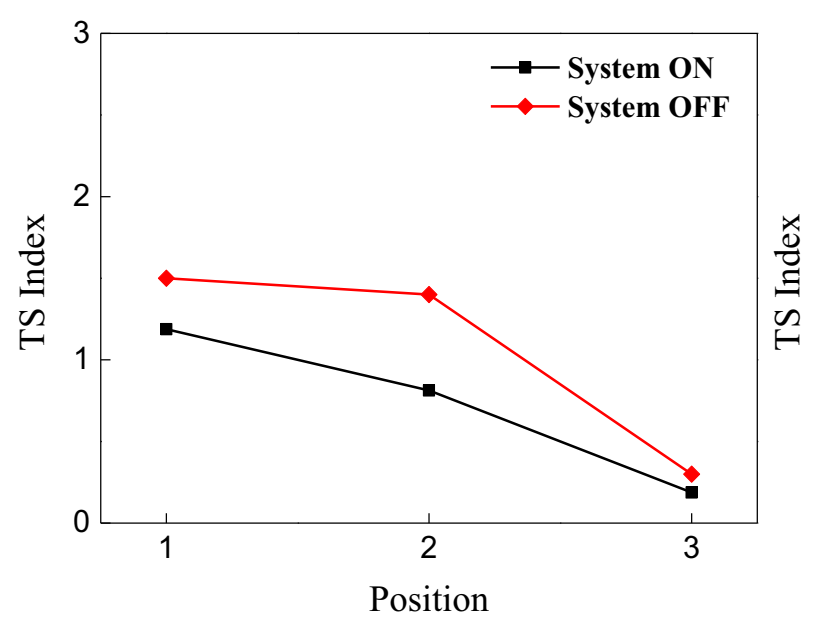

(d)

Fig. 12. Effect of air impingement on the traveling stability for different strip sizes (thickness $\times$ width): (a) $1.32 \mathrm{~mm} \times 1000 \mathrm{~mm},(\mathrm{~b})$ $1.52 \mathrm{~mm} \times 1052 \mathrm{~mm}$, (c) $1.9 \mathrm{~mm} \times 1175 \mathrm{~mm}$, (d) $2.15 \mathrm{~mm} \times 833 \mathrm{~mm}$.

\section{Nomenclature}

$B$ Height of air nozzle

$W$ Width of air nozzle

$\theta \quad$ Tilting angle of air nozzle

$H \quad$ Distance between nozzle exit and impingement surface

$U$ Inlet velocity of air shooting nozzle

$V \quad$ Velocity of moving strip

Acknowledgements. This work was supported by the National Research Foundation of Korea (NRF) grant with funding from the Korean government (MSIP) (No. 2012R1A5A1048294).

\section{References}

1 S.J. Chen, A.A. Tseng, Spray and jet cooling in steel rolling, Int. J. Heat Fluid Flow 13 (1982) 358-369
2 S.J. Chen, J. Kothari, A.A. Tseng, Cooling of a moving plate with an impinging circular water jet, Exp. Therm. Fluid Sci. 4 (1991) 343-353

3 J.H. Seo, C.J. Van Tyne, Y.H. Moon, Effect of roll configuration on the leveling effectiveness of tail-up bent plate using finite element analysis, J. Manuf. Sci. Eng. 138 (2016) 1-7

4 N. Karwa, P. Stephen, Experimental investigation of freesurface jet impingement quenching process, Int. J. Heat Mass Transf. 64 (2013) 1118-1126

5 Y.H. Moon, D.W. Kim, C.J. Van Tyne, Analytical model for prediction of sidewall curl during stretch-bend sheet metal forming, Int. J. Mech. Sci. 50 (2008) 666-675

6 S.M. Byon, S.R. Kim, T.Y. Kim, Y.S. Lee, An approximate model to predict the surface profile of material sections in a 3roll rolling process, J. Mech. Sci. Technol. 31 (2017) 3489-3497

7 H.K. Yi, D.W. Kim, C.J. Van Tyne, Y.H. Moon, Analytical prediction of springback based on residual differential strain during sheet metal bending, J. Mech. Eng. Sci. 222 (2008) $117-129$ 
8 X. Wang, Q. Yang, A. He, Calculation of thermal stress affecting strip flatness change during run-out table cooling in hot steel strip rolling, J. Mater. Process. Technol. 207 (2008) 130-146

9 T.D. Kil, J.M. Lee, Y.H. Moon, Quantitative formability estimation of ring rolling process by using deformation processing map, J. Mater. Process. Technol. 220 (2015) 224-230

10 A.H. Nobara, V. Prodanovic, M. Militzer, Heat transfer of a stationary steel plate during water jet impingement cooling, Int. J. Heat Mass Transf. 101 (2016) 1138-1150

11 M.L. Hosain, R.B. Fdhila, A. Daneryd, Heat transfer by liquid jets impinging on a hot flat surface, Appl. Energy 164 (2016) 934-943

12 G. Jia, M. Cai, Y. Shi, W. Xu, The experimental analysis of the water spray cooling compressed air, Mechanics \& Industry 18 (2017) 211

13 Q. Guo, Z. Wen, R. Dou, Experimental and numerical study on the transient heat transfer characteristics of circular airjet impingement on a flat plate, Int. J. Heat Mass Transf. 104 (2017) 1177-1188

$14 \mathrm{H}$. Martin, Heat and mass transfer between impinging gas jets and solid surfaces, Adv. Heat Transf. 13 (1977) $1-60$

15 K. Jambunathan, E. Lai, M.A. Moss, B.L. Button, A review of heat transfer data for single circular jet impingement, Int. J. Heat Fluid Flow 13 (1992) 106-115

16 N. Zuckerman, N. Lior, Jet impingement heat transfer: physics, correlations, and numerical modeling, Adv. Heat Transf. 39 (2006) 565-631

17 Y.T. Ren, X.M. Qiu, T.X. Yu, Verification of a theoretical model of tensor skin under water impact by considering the fluid-structure interaction, Int. J. Impact Eng. 92 (2016) $66-74$
18 M. Ahsan, A. Hussain, A computational fluid dynamics (CFD) approach for the modeling of flux in a polymeric membrane using finite volume method, Mech. Ind. 18 (2017) 406

19 X. Wang, F. Li, Q. Yang, A. He, FEM analysis for residual stress prediction in hot rolled steel strip during the run-out table cooling, Appl. Math. Model. 37 (2013) 586-609

20 A. Malik, R.V. Grandhi, A computational method to predict strip profile in rolling mills, J. Mater. Process. Technol. 206 (2008) 263-274

21 A. Kaliazine, M. Eslamian, N.H. Tran, On the failure of a brittle material by high velocity gas jet impact, Int. J. Impact Eng. 37 (2010) 131-140

22 Y. Lu, F. Huang, X. Liu, X. Ao, On the failure pattern of sandstone impacted by high-velocity water jet, Int. J. Impact Eng.r 76 (2015) 67-74

23 S.M. Salim, S. Cheah, Wall $y^{+}$strategy for dealing with wallbounded turbulent flows, Proceedings of the International MultiConference of Engineers and Computer Scientists, Hong Kong, China (2009)

24 D. Singh, B. Premachandran, S. Kohli, Double circular air jet impingement cooling of a heated circular cylinder, Int. J. Heat Mass Transf. 109 (2017) 619-646

25 H.N. Han, J.K. Lee, H.J. Kim, Y.S. Jin, A model for deformation, temperature and phase transformation behavior of steels on run-out table in hot strip mill, J. Mater. Process. Technol. 128 (2002) 216-225

26 H. Wang, W. Yu, Q. Cai, Experimental study of heat transfer coefficient on hot steel plate during water jet impingement cooling, J. Mater. Process. Technol. 212 (2012) $1825-1831$

27 D. Singh, B. Premachandran, S. Kohli, Effect of nozzle shape on jet impingement heat transfer from a circular cylinder, Int. J. Therm. Sci. 96 (2015) 45-69

Cite this article as: Y.Y. Woo, S.W. Han, J.R. Cho, Y.H. Moon, Air jet impingement to reduce hot strip wave on a run-out table, Mechanics \& Industry 19, 601 (2018) 